\title{
Adrenal Androgen Deficiency
}

National Cancer Institute

\section{Source}

National Cancer Institute. Adrenal Androgen Deficiency. NCI Thesaurus. Code C113203.

Abnormally low or absent secretion of the androgen precursor hormones

dehydroepiandrosterone (DHEA), DHEA sulfate, and androstenedione, from the adrenal gland. 